\title{
GESTÃO DE COMPRAS EM ORGANIZAÇÕES PÚBLICAS: UM ESTUDO DE CASO A PARTIR DAS AQUISIÇÕES DA UFT ENTRE OS ANOS DE 2012 A $2016^{1}$
}

\author{
Purchase management in public organizations: \\ a case study from UFT acquisitions between \\ the years 2012 to 2016
}

Pedro Junior Lima Sousa

Ana Lucia de Medeiros

\section{RESUMO}

As organizações empresariais estão reorientando suas práticas para otimização de seus fluxos operativos visando uma gestão mais eficiente. Este cenário de racionalização administrativa também está impactando as organizações públicas. Nesta perspectiva, a busca por uma gestão mais efetiva está levando as organizações públicas a buscarem novas respostas para equacionar suas limitações orçamentárias. Este trabalho tem como objetivo estu- dar a gestão de compras da Universidade Federal do Tocantins, entre 2012 e 2016. Esta pesquisa é um estudo de caso e foi feita a partir de análise de documentos institucionais e pesquisa bibliográfica. Do volume total contratado de 2012 a 2016 a maior parte foi destinada à contratação de serviços, com aplicação de $72,05 \%$ do volume total. As contratações realizadas por meio de contratação direta representam $73,85 \%$ do número de processos, o que pode sinalizar fragilidade no controle 
referente ao fracionamento das aquisições. Observou-se que a UFT utiliza como forma predominante para suas aquisições o pregão na sua forma eletrônica, do volume financeiro total contratado $73,91 \%$ foi por esta modalidade. Mesmo com o cenário de restrição fiscal, foi observado um crescimento no valor global das aquisições a partir de 2014. Os resultados demonstraram que a universidade ainda carece de melhorias robustas no acompanhamento dos processos de compras, especialmente no que se refere à agilidade do processamento das demandas. O que pode ajudar a entender esses resultados é a necessidade de cumprimento de ritos legais associada à realidade multicampi da Universidade, o que dificulta ações coordenadas entre as unidades administrativas.

Palavras-chave: Gestão de compras, Otimização. Universidade Federal do Tocantins.

\section{ABSTRACT}

Business organizations are reorienting their practices to optimize their operating flows for more efficient management. This scenario of administrative rationalization is also impacting public organizations. In this perspective, the search for more effective management is leading public organizations to seek new answers to address their budgetary limitations. This work aims to study the purchasing management of the Federal University of Tocantins, between 2012 and 2016. This research is a qualitative case study and was conducted with the analysis of institutional documents and bibliographic research. Of the total volume contracted from 2012 to 2016, 72.05\% of the total volume was destined to contract services. Hiring through direct contracting represents $73.85 \%$ of the number of processes, which may signal weakness in the control related to the fractioning of acquisitions. It was observed that UFT uses the electronic auction as its predominant form for its acquisitions, of the total financial volume contracted $73.91 \%$ was through this modality. Even with the fiscal constraint scenario, there was an increase in the global value of acquisitions from 2014 . The results showed that the university still lacks robust improvements in the monitoring of procurement processes, especially with regard to the agility of processing orders. demands, which may be explained by the University's multi-camp reality that makes coordinated actions between administrative units difficult.

Keywords: Purchasing management, Optimization. Federal University of Tocantins.

A partir da década de 1990, a Administração Pública reorientou suas ações pela busca por eficiência. Nesta nova visão de busca por uma maior racionalidade administrativa, visa adequar os recursos disponíveis diante dos fins desejados. Nessa discussão, são apresentados novos instrumentos de respostas à equação da eficiência, ao possibilitar a otimização dos limitados recursos à disposição destas organizações (GOMES, 2009). 
No âmbito desta perspectiva, as universidades enquanto organizações complexas (LEITÃO, 1985) estão imersas nestes desafios contemporâneos. No entanto, devido ao ambiente universitário, onde atuam diferentes atores em espaços de decisões colegiadas, que vislumbram a atividade universitária em uma perspectiva que transcende simplesmente a dimensão de custos. Logo, a formação de consenso em torno de suas prioridades se torna um desafio constante.

Portanto, a crescente cobrança pela racionalização administrativa, impulsionam as universidades públicas a buscarem novas soluções para equacionar as suas limitações cotidianas, porém, dados os incipientes modelos de sucesso limitam a um direcionamento (SGUISSARDI, 2009). Tornando-se deste modo inevitável avaliar os seus processos rumo a uma gestão que possa maximizar os seus resultados. No âmbito desta discussão, este trabalho se propõe a buscar novos mecanismos que permitam melhorar a efetividade da gestão dos recursos à disposição da Universidade.

Nesse complexo ambiente, os gestores se veem cercados de grandes desafios para consecução dos objetivos institucionais, e neste cenário as compras públicas adquirem uma posição estratégica, devido à concentração do alto poder aquisitivo do Estado. Deste modo, as compras públicas se tornam o canal operativo que viabiliza o ciclo das políticas públicas (A3P, 2016).

Partindo dessas observações, este estudo se baseia em como se comportou o setor de compras da Universidade Federal do Tocantins entre os anos de 2012 a 2016. Então, este período foi selecionado no intuito de sistematizar um parâmetro de análise para atividade de compras, de modo que até 2014 não era conhecida à extensão da grave crise fiscal que o país sucumbiu pós-período eleitoral, colocando em perspectiva temporal uma fase com potencial de retratar a transição da Administração Pública para um cenário de maior restrição fiscal, que exige um comportamento mais profissional da gestão como um todo.

Os resultados aqui apresentados são frutos de um trabalho mais amplo de uma dissertação de mestrado apresentada em 2018. O estudo se torna relevante, por pesquisar soluções para gestão de compras em organizações públicas, podendo ser utilizado como ferramenta de otimização da atividade, com a identificação dos possíveis gargalos, para, caso necessário, sejam propostas alternativas para os desafios encontrados, possibilitando assim a constituição de um parâmetro para aperfeiçoar a gestão universitária. 


\section{COMPRAS PÚBLICAS, APRESENTADAS COMO INSTRUMENTOS DE DESENVOLVIMENTO DE POLÍTICAS PÚBLICAS}

$\mathrm{Na}$ administração da coisa pública, ressalvadas algumas excepcionalidades legais, a orientação é licitar, garantindo não só atendimento à legislação, mais uma saudável concorrência. Dentro desta concepção, o principal canal operativo das compras públicas é o processo licitatório.

Logo, se torna imperativo trazer o conceito de eficiência do mainstream do mercado, para um cenário onde estão inclusos novos desafios presentes na Administração Pública, que não estão postos da mesma forma para iniciativa privada, qual seja, os princípios constitucionais que proporcionam a legalidade dos atos públicos, a serem garantidos pela aplicação minuciosa dos diversos dispositivos legais na instrução dos complexos processos de compras públicas.

Para sucesso nessa precisão conceitual, partiu-se das observações que diferente da eficiência, a efetividade não é um conceito econômico, mas sim de avaliação qualitativa dos serviços públicos. Portanto, no conceito de efetividade resgata a orientação que acima de tudo o governo deve prestar serviços com uma boa qualidade ao seu público (ABRUCIO, 1997), esta concepção está em linha com as afirmações Osborne e Gaebler (1994) em sua obra Reinventado o Governo, na perspectiva da obra a efetividade dimensiona o grau em que determinada ação do governo atingiu o resultado esperado.

Por sua vez, a eficiência é um conceito econômico, tendo em vista que a sua busca fomenta a consciência de custos, voltado a medição do que foi ou será produzido (ABRUCIO, 1997). Neste viés, se restringir a análise apenas a eficiência, acredita-se que a finalidade deste trabalho possa estar comprometida, pois ao considerar apenas a eficiência como um fim em si mesma, limitar-se-ia a percepção de melhoria na prestação dos serviços públicos, que pode ser dimensionado com o conceito de efetividade.

Esta orientação é reforçada por Osborne e Gaebler (1994), pois para os autores a avaliação da eficiência não pode estar dissociada do dimensionamento da efetividade, tendo em vista que a eficiência aufere o custo do que está sendo produzido, ao passo que, a efetividade mede a qualidade dos resultados auferidos. Deste modo, a eficiência precifica o custo operacional de determinada atividade e a efetividade vem como uma orientação complementar, porém fundamental, pois estima se este investimento vale a pena. 
Não adiantaria baixarmos o custo de transação do serviço público sacrificando a efetividade dos resultados, como bem destaca Flynn (1990) ao analisar a experiência da Grã-Bretanha a "imposição arbitrária da diminuição dos custos" conduz "mais à redução do nível (de qualidade) dos serviços do que a um aumento de produtividade". Logo, torna-se oportuno convergir este achado com a análise proposta neste trabalho. Após estas ponderações que ilustram a importância da reflexão sobre o tema, pode-se adentrar a realidade específica da Universidade. No que se refere ao gerenciamento dos seus recursos ela goza de relativa autonomia, uma vez que cabe a ela estabelecer procedimentos gerenciais com vistas a alcançar os seus fins. Nesta perspectiva, o princípio da autonomia universitária já é uma realidade que permite a Universidade estabelecer seus fluxos que objetive promover a inovação em suas práticas administrativas.

Não obstante, esta dimensão está em linha com as prioridades institucionais a serem pautadas no Plano de Desenvolvimento Institucional que referencia a atuação das Universidades no médio prazo. Nesta perspectiva, a gestão de compras, enquanto atividade meio, exerce um papel importante para viabilizar o sucesso das atividades finalísticas, tendo em vista que é por seu meio onde são canalizados a aplicação dos recursos institucionais.

Adiciona-se a esta discussão a orientação da Administração Pública Brasileira a New Public Management pós-Reforma do Estado (BRESSER-PEREIRA, 2002), com a elaboração de importantes dispositivos legais que regulamentaram a atividade de compras, como a Lei $n^{\circ}$ 8.666/1993 de Licitações e Contratos, a Lei $n^{\circ} 10.520 / 2002$ do Pregão e a sua forma eletrônica regulamentada pelo Decreto $\mathrm{n}^{\circ} 5.450 / 2005$ operacionalizado pelos Comprasnet, a Lei no 12.462/2011 do Regime Diferenciado de Contratações, regulamentada pelo Decreto $n^{\circ} 7.581 / 2011$ e o Decreto 7.892/2013 que referencia o Sistema de Registros de Preços.

No entanto, este arcabouço legal referencia apenas de forma normativa às contratações públicas, focando no aumento da transparência e controle da administração pública por meio do cumprimento de ritos. Contudo, deve-se priorizar o combate a este excesso de formalismo reorientando as novas práticas pela busca por eficiência, otimizando a relação custo x benefício (FIUZA; MEDEIROS, 2013).

Partindo deste contexto, acredita-se que o princípio da eficiência nestas instituições dever ser entendido não só pelo managerialism do $\mathrm{New} \mathrm{Pu}$ blic Management (NPM), uma relação de causa e efeito. Devendo ser incluí- 
do nesta análise fatores ambientais e cognitivos que influenciam a gestão de seus processos, constituindo uma relação intersubjetiva entre a intenção no planejamento e a execução das ações pelos diversos atores que interagem em um ambiente dinâmico (CORAIOLA; MACHADO-DA-SILVA, 2008), com objetivos a serem cumpridos, com servidores com diferentes competências e perspectivas quanto à carreira e à própria vida.

Portanto, mais do que um cálculo apenas utilitarista, o conceito de eficiência para organizações universitárias deve ser incluído o arcabouço legal que referencia a execução da sua atividade. Todavia, a verticalização e a departamentalização destas estruturas universitárias (MOTTA; AGUIAR, 2007), influenciam nos seus processos de aquisições, tudo isso legitimados pelas suas decisões majoritariamente colegiadas.

Nesta perspectiva, a gestão de compras tem valor estratégico para Batista e Maldonado (2008, p. 685-686), pois está contida na "gestão de suprimentos que por sua vez é um dos pilares de qualquer instituição pública", pois é reconhecidamente onde se "aplicam os recursos orçamentários", ao qual são assimilados os objetivos institucionais, propiciando pelo seu fluxo constante o correto atendimento das suas especificidades.

Portanto, a atividade de compras para as organizações públicas se tornou de certa forma uma vantagem competitiva, dado o contexto de limitação orçamentária vigente, onde é imperativo o senso de urgência pelos administradores públicos da necessidade de dar mais celeridade a este processo, com objetivo de se buscar uma melhor relação custo X benefício.

\section{PROCEDIMENTOS METODOLÓGICOS}

Para sistematização dos objetivos desta pesquisa são necessárias algumas delimitações metodológicas do objeto em estudo. A pesquisa qualitativa é indicada para estudos que visam o aprofundamento nos fenômenos sociais, neste aspecto, a natureza metodológica da pesquisa que se apresenta a seguir tem um caráter majoritariamente qualitativo, por mais que se utiliza de dados que foram quantificados, parte-se da premissa que os dados em sua forma bruta precisam ser contextualizados dentro de um complexo ambiente de interações que é a universidade pública.

Para classificação deste estudo, toma-se por base a taxonomia apresentada por Vergara (2011), ao dividir a metodologia quanto aos meios e aos fins.

Quanto aos meios, é um estudo de caso em uma organização governamental específica, em um contexto delimitado, com a utilização da pesquisa bi- 
bliográfica e a pesquisa documental, e consulta a base de dados do governo federal, com a triangulação das informações para maior embasamento empírico.

Quanto aos fins é uma pesquisa descritiva. Neste sentido Vergara (2011, p. 42) entende que a pesquisa descritiva expõe características do fenômeno estudado, podendo inclusive identificar correlação entre variáveis. Porém não assume compromisso de explicar os fenômenos ao qual descreve, muito embora, são úteis para explicação do fenômeno observado. É descritiva por buscar identificar as características ambientais da Universidade envolvida, estabelecendo relações com os processos em análise.

\section{RESULTADOS}

A UFT veio para atender a um passivo social existente no Estado do Tocantins, permitindo por meio de sua alta capilaridade em sete unidades acadêmicas, levar à comunidade a possibilidade de ingresso no ensino superior gratuito em diferentes pontos regionais, dado sua conformação estrutural em formato multicampi. (LIMA, 2015).

No âmbito destes desdobramentos, a consolidação da fundação da UFT foi por meio da Lei $n^{\circ} 10.032$, de 23 de outubro de 2000, constituindo-se assim em uma entidade jurídica de direito público, dotada de autonomia didático-financeira e de gestão administrativa financeira e patrimonial, com sede e foro na cidade de Palmas, Capital do Estado.

$\mathrm{Na}$ Reitoria, são concentradas as atividades executivas da Universidade, como o caso da coordenação e fiscalização das atividades tanto acadêmicas quanto administrativas. Para suporte a esta atividade executiva a Universidade dispõe de seis Pró-Reitorias, que se dedicam as áreas de: Graduação (Prograd), Pesquisa (Propesq), Extensão (Proext), Administração e Finanças (Proad), Planejamento (Proap), Assuntos Estudantis (Proest), adicionados a esta estrutura, tem-se a atuação da Prefeitura Universitária, que dá suporte a infraestrutura geral da Universidade. Nesta perspectiva, estas estruturas atuam de forma coordenada no suporte ao ensino e a sua estrutura administrativa.

De acordo com o Relatório de Gestão da UFT (2014, p. 21), a sua estrutura de governança é orientada em função das suas prioridades institucionais, que por sua vez ancoram os eixos estratégicos que direcionam a atuação da Universidade, quais sejam: "ensino de qualidade, comprometido com valores étnicos, sociais e culturais; conhecimento, inovação, transparência, compromisso social e respeito à diversidade; gestão inovadora, transparente e responsável". 
A segunda parte desta discussão é direcionada ao dimensionamento das características do ciclo de compras na Universidade. Com base nesta perspectiva, apresenta-se, na sequência, o perfil geral das aquisições da Universidade no interstício de 2012 a 2016, a intenção é criar a possibilidade de mostrar o processo de aquisições em um cenário de médio prazo, conforme pode ser observado na Tabela 1.

TABELA 1: VALOR CONSOLIDADO DAS AQUISIÇÕES DA UFT DE 2013 A 2016

\begin{tabular}{cccc}
\hline & \multicolumn{3}{c}{ Compras totais (mil R\$) } \\
\hline Ano & Qte & VALOR DAS COMPRAS ANO A ANO & Valor das Compras \\
\hline 2012 & 157 & $31.993,46$ & 10,2 \\
2013 & 143 & $90.327,52$ & 28,81 \\
2014 & 121 & $49.754,19$ & 15,87 \\
2015 & 97 & $67.161,74$ & 21,42 \\
2016 & 136 & $74.275,40$ & 23,69 \\
\hline Total & 654 & $313.512,31$ & 100 \\
\hline
\end{tabular}

FONTE: Elaborado pelo autor a partir dos dados do MPOG - Painel de Compras (2017)

Pretende-se com a tabela desenhar uma perspectiva macro do volume dos recursos utilizados pela Universidade nos cinco anos de referência. É observado que o período de maior expressividade do volume aplicado foi no ano de 2013, seguidos de 2014 ao seu segundo menor nível nos dados observados, em frente apenas do ano de 2012. Nos dois últimos anos, visualiza-se novamente um movimento de expansão das aquisições, porém não em nível observado em 2013.

Diante destas impressões, nos impõe a buscar uma reflexão que se faça coerente com esta realidade observada, no âmbito dessa reflexão, 2014 foi o ano em que foi percebida a dimensão da real situação fiscal do país, o que pode ter tido impacto na situação apresentada, visto após 2014 os contingenciamentos de recursos públicos se tornou assunto frequente nos diversos órgãos de governo, tendo em vista a dificuldade de o governo central cumprir a meta fiscal, necessitando de ajustes junto à estrutura governamental para controle mais efetivo do volume de recursos neles aportados.

Depois dessa perspectiva inicial, torna-se necessário buscar as especificidades deste panorama macro, na tentativa de buscar demonstrar as peculiaridades operacionais do processo de compras pela Universidade. Abaixo é apresentada a composição destas aquisições, demonstrando como estes 
processos estão sendo geridos pela Universidade, apresentando quais as modalidades licitatórias mais são utilizadas para viabilizar as suas necessidades.

TABELA 2: PERFIL DOS PROCESSOS DE COMPRAS REALIZADOS DE 2012 A 2016 NA UFT

(Mil R\$)

Perfil das compras por quantidade de processos realizados de 2012 a 2016

\begin{tabular}{lcccc}
\hline Modalidade de Compras & Qte & $\%$ & Valor & $\%$ \\
\hline Pregão & 138 & 21,1 & $231.729,82$ & 73,91 \\
Concorrência & 14 & 2,14 & $28.922,87$ & 9,23 \\
Tomada de Preços & 14 & 2,14 & $3.809,29$ & 1,22 \\
Convite & 5 & 0,76 & 272,57 & 0,09 \\
Dispensa de Licitação & 296 & 45,26 & $36.197,17$ & 11,55 \\
Inexigibilidade de Licitação & 187 & 28,59 & $12.580,60$ & 4,01 \\
\hline Total de processos & 654 & 100,00 & $313.512,31$ & 100,00 \\
\hline
\end{tabular}

FONTE: Elaborado pelo autor a partir dos dados do MPOG - Painel de Compras (2017)

Depreende-se da tabela acima que é possível olhar o perfil dos processos de aquisições da Universidade para o interstício informado por duas perspectivas diferentes, uma primeira voltada para ao quantitativo de processos e outra voltada ao valor global das aquisições por suas respectivas modalidades licitatórias.

Desse modo, pela sua primeira perspectiva é observado que a Universidade concentra grande parte do quantitativo de processos de aquisições em contratações diretas, ou seja, utilizam mecanismos que dispensam o processo licitatório, deste modo, são utilizadas as exceções legais para balizar o processo da tomada de decisão para definição do tipo recomendado de modalidade licitatória a ser utilizada.

Ao quantificar esta perspectiva $45,26 \%$ do quantitativo total das aquisições da Universidade para o período foram efetivadas por meio da dispensa de licitação e se for adicionado a este cenário a inexigibilidade, chega-se a incríveis $73,85 \%$ das aquisições sendo feitas por meio de contratação direta, não passando assim pelo processo de concorrência pública.

Todavia, na segunda perspectiva, ao considerar as modalidades que mais concentram o volume de recursos aportados das aquisições, nota-se a modalidade mais utilizada é a contratação indireta, sendo que apenas o pre- 
gão ${ }^{3}$ concentra $73,91 \%$ de todo o volume contratado pela Universidade, ao passo que as contratações diretas por meio da dispensa ou da inexigibilidade juntas somam apenas 15,56\%.

O que leva ao questionamento das especificidades que colocam as duas perspectivas dimensionadas em conflito, pois se pelo volume da quantidade de processos gerados tem-se a contratação direta sendo a forma predominante, contudo, por que a análise pelo valor global contratado tem efeito contrário? Estando concentrado nas contratações indiretas como no exemplo o pregão.

O que sugere estudos específicos mais profundos sobre o possível fracionamento ou não das compras pelas unidades gestoras. Como fator que impacta neste cenário, tem-se a estrutura multicampi da Universidade, o que reforça a necessidade de conhecer estas especificidades para impor limites e minimizar a exposição aos órgãos de controle externo, visto o caso do fracionamento das compras públicas visando contratação simplificada, já há entendimento pelos órgãos de controle que ela deve ser evitada.

Esta percepção aguça interesse, pois o pregão via SRP é justamente para proporcionar um ganho de escala para administração pública minimizando o risco de fracionamento, ao permitir o planejamento de demandas conjuntas entre as unidades gestoras para serem atendidas pelo prazo de até um ano da sua homologação, se tornando um importante instrumento que permite diminuir o custo de transação do processo licitatório, ao passo que a fragmentação em vários processos vai na contramão desta perspectiva, ao impactar no aumento do custo das operações, visto que serão necessários mais recursos para publicação de edital em mídias especializadas, e no próprio diário oficial. Além da característica multicampi, o que pode levar a sobreposição do objeto pelas Unidades Gestoras, ou seja, produtos semelhantes em processos diferentes.

Outra característica diagnosticada das compras da Universidade é que estas se concentram em grande parte em contratações de serviços, representando $72,05 \%$ do total contratado.

No que se refere ao papel social da Universidade direcionada a sua política de aquisições, apenas $0,46 \%$ de suas aquisições tiveram itens susten-

3 De acordo com o MPOG atualmente Ministério da Economia - Painel de Compras (2017), a Universidade utilizou no ano de 2014 apenas o pregão na sua forma eletrônica 
táveis no período, o que reflete uma baixa percepção da Universidade em melhorar o impacto social das suas aquisições.

Santos (2016) corrobora com esta assertiva, tendo em vista que alguns de seus resultados reforçam a baixa percepção da Universidade para aumentar a relevância dos itens com critérios de sustentabilidade nas suas aquisições. Para justificar este fato, afirma que os critérios de inclusão destes itens não são sistematizados, ficando muito mais a cargo da escolha do gestor, do que condicionado em ferramenta formal.

Em complemento a esta perspectiva, segundo dados do Painel De Compras (2017), 56,07\% das aquisições foram homologadas para Microempresas - ME e Empresas de Pequeno Porte - EPP, este resultado é reforçado pelos estudos de Santos (2016), ao firmar entendimento que a Universidade vem empreendendo medidas para conceder prerrogativas as ME/EPP. Todavia, a autora faz ressalvas, como o baixo nível de inclusão de critérios discricionários nas aquisições, como a inclusão de: possibilidade da cláusula de subcontratação de ME/EPP; margem de preferência regional; cota para mulheres em contratos que exijam mão de obra.

Todavia, para o uso dos conceitos subjacentes as compras sustentáveis devem ser monitoradas e, na medida do possível, fomentadas o mercado fornecedor destes bens e produtos para fornecimento junto à administração pública. É de se destacar a importância de ponderar a oferta incipiente, pois a pouco interesse na baixa competitividade inerente a estas aquisições.

O que reflete diretamente no aumento do custo da transação, ou seja, há um impacto direto na percepção do gestor público ante o contexto vigente de limitação orçamentária, levando-o a um paradoxo, ao mesmo tempo do cenário fiscal que se apresenta e a própria busca por economicidade, tem em contraponto o seu dever legal de implementar o desenvolvimento por meio de aquisições sustentáveis, adicionando critérios socioambientais nas contratações (SILVA; BARKI, 2012).

Uma alternativa para viabilizar o aumento da competitividade por bens produtos sustentáveis é as organizações governamentais viabilizarem suas contratações por meio de compras compartilhadas com outros órgãos governamentais por meio do SRP. Nesta perspectiva, tem-se o trabalho de Silva e Barki (2012), dentre alguns de seus achados o ganho em escala aumenta o volume da quantidade a ser adquirida, no caso que analisaram o aumento do volume representou uma economia de $50 \%$ do valor final contratado. 
Portanto, é observado um efeito positivo no aumento do interesse do fornecimento deste tipo de bens pelos mercados, o que foi benéfico para a diminuição do custo final da aquisição, deste modo, com base nessas considerações é demonstrada a viabilidade de alternativas para a UFT melhorar sua performance atual em relação ao aumento da participação de itens sustentáveis em seus processos de aquisições.

\section{CONSIDERAÇÕES FINAIS}

Este trabalho teve seu ponto de partida nas inquietações deste pesquisador enquanto servidor público em propor uma reflexão do papel da Universidade Federal enquanto formadora de seres pensantes para a sociedade contemporânea. A esta perspectiva inicial somou-se o contexto de limitação orçamentária vigente, que vem impactando o funcionamento da administração pública brasileira.

Para o sucesso desta pesquisa, buscou-se construir uma linha de raciocínio onde pudesse ser apresentados um panorama do processamento de compras da Universidade, além de fazer uma reflexão do processamento das compras da Universidade a partir da caracterização do ambiente institucional que a envolve.

Por meio da análise dos resultados deste trabalho, é perceptível que a Universidade Federal do Tocantins possui algumas fragilidades em proporcionar ações integradas na execução do processamento de compras entre as suas diversas unidades administrativas, principalmente quando considera o acompanhamento dos processos visando à mitigação de seu fracionamento, representado pelas contratações diretas.

Contudo, a estrutura organizacional em certa medida permite a operação de ações conjuntas entre as unidades administrativas, o que precisa ser otimizado é focar essa integração rumo a superar as deficiências operacionais diagnosticadas.

Mesmo com o cenário de restrição fiscal, foi observado um crescimento no valor global das aquisições a partir de 2014. Os resultados demonstraram que a universidade ainda carece de melhorias robustas no acompanhamento dos processos de compras, especialmente no que se refere à agilidade do processamento das demandas, o que pode ajudar a entender esses resultados é a necessidade de cumprimento de ritos legais associada à realidade multicampi da universidade, o que dificulta ações coordenadas entre as unidades administrativas. 
Como sugestão interessante para estudos futuros é buscar dimensionar a perspectiva da efetividade do processamento de compras da Universidade a partir da visão do usuário final, deste modo, as diferentes perspectivas podem ser comparadas aos resultados deste trabalho.

Dentre às limitações de abordagem desta pesquisa, destaca-se o recorte temporal utilizado para levantamento empírico, em que se partiu de uma inquietação própria do pesquisador enquanto incluso neste cenário, logo, recomenda-se a proposição de novos estudos a partir de uma perspectiva mais ampla.

\section{REFERÊNCIAS}

ABRUCIO, F. L. O impacto do modelo gerencial na Administração Pública: um breve estudo sobre a experiência internacional recente. ENAP. Caderno 10.

A3P - Agenda Ambiental na Administração Pública. Notícias A3P. 2016. Disponível em: <http://www.mma.gov.br/responsabilidadesocioambiental/ a3p/eixostematicos/item/529>. Acesso em: 15 abr. de 2017.

BATISTA, M. A. C.; MALDONADO, J. M. S. de V. O papel do comprador no processo de compras em instituições públicas de ciência e tecnologia em saúde (C\&T). RAP, Rio de Janeiro, v. 42, n. 4, p. 681-99, jul. /ago. 2008.

BRASIL. Decreto no 5.450, de 31 de maio de 2005. Regulamenta o pregão, na forma eletrônica, para aquisição de bens e serviços comuns, e dá outras providências. Diário Oficial da União, Brasília, DF, 1 jun. 2005. Disponível em: <http://www.planalto.gov.br/ccivil_03/_ato20042006/2005/decreto/d5450.htm>. Acesso em: 10 out. 2020.

BRASIL. Decreto $n^{\circ} 7.581$, de 11 de outubro de 2011. Institui o Regulamento do RDC. Diário Oficial da União, Brasília, DF, 24 jan. 2013. Disponível em: <http://www.planalto.gov.br/ccivil_03/_Ato20112014/2011/Decreto/D7581.htm>. Acesso em: 20 jun. 2020.

BRASIL. Decreto $n^{\circ} 7.892$, de 23 de janeiro de 2013. Regulamenta o pregão, na forma eletrônica, para aquisição de bens e serviços comuns, e dá outras providências. Diário Oficial da União, Brasília, DF, 24 jan. 2013. Disponível em: <http://www.planalto.gov.br/ccivil_03/_ Ato20112014/2013/Decreto/D7892.htm>. Acesso em: 20 jun. 2020.

BRASIL. Lei no 8.666, de 21 de junho de 1993. Regulamenta o art. 37, inciso XXI, da Constituição Federal, institui normas para licitações e contratos da Administração Pública e dá outras providências. Diário Oficial da União, Brasília, DF, 22 jun. 1993. 
BRASIL. Lei no 10.032, de 23 de outubro de 2000. Institui a Criação da Universidade Federal do Tocantins. Diário Oficial da União, Brasília, DF, 23 out. 2000 .

BRASIL. Lei $\mathrm{n}^{\circ}$ 10.520, de 17 de julho de 2002. Institui, no âmbito da União, Estados, Distrito Federal e Municípios, nos termos do art. 37, inciso XXI, da Constituição Federal, modalidade de licitação denominada pregão, para aquisição de bens e serviços comuns, e dá outras providências. Diário Oficial da União, Brasília, DF, 18 jul. 2002.

BRASIL. Lei no 12.462, de 4 de agosto de 2011. Institui o Regime RDC. Diário Oficial da União, Brasília, DF, 4 ago. 2011.

BRESSER PEREIRA, L. C. Uma resposta estratégica aos desafios do capitalismo global e da democracia. In: BRASIL. Ministério do Planejamento, Orçamento e Gestão. Balanço da reforma do Estado no Brasil: a nova gestão pública. Brasília, p.29-35. Mimeo. Seminário de 06 a 08 de agosto de 2002.

CORAIOLA, D. M.; MACHADO-DA-SILVA, C., L. Discurso organizacional e isomorfismo institucional: as mudanças. Revista Eletrônica de Ciência Administrativa - RECADM, v. 7, n 2, p. 1-13, 2008.

FIUZA, E. P. S.; MEDEIROS, B. A. de. A reforma da Lei 8.666/93 e do arcabouço legal de compras públicas no Brasil: contribuições do Ipea à Consulta Pública do Senado. Nota técnica IPEA, n. 8, Brasília, 2013.

FLYNN, N. Public sector management. New York/London: Harvester Wheatsheaf. 1990.

GOMES, E. G. M. Gestão por resultados e eficiência na administração pública: uma análise à luz da experiência de Minas Gerais. São Paulo: EAESP/FGV, 187 p. (Tese de Doutorado apresentada ao Curso de Doutorado de Administração Pública e Governo da EAESP/FGV, Área de Concentração: Transformações do Estado e Políticas Públicas). 2009.

LEITÃO, S. P. A questão organizacional na universidade: as contribuições de Etzioni e Rice. Rev. Adm. Pública-RAP, v. 19, n. 4, p. 3-26, out/dez. 1985

LIMA, J. N. Planejamento e orçamento como instrumentos de gestão: o caso da Universidade Federal do Tocantins. Dissertação (Mestrado Profissional). UFT. Mestrado Profissional em Gestão de Políticas Públicas, Palmas-TO. 2015.

MOTTA, L. B.; AGUIAR, A. C. Novas competências profissionais em saúde e o envelhecimento populacional brasileiro: integralidade, 
GESTÃO DE COMPRAS EM ORGANIZAÇÕES PÚBLICAS: UM ESTUDO DE

CASO A PARTIR DAS AQUISIÇÕES DA UFT ENTRE OS ANOS DE 2012 A 2016

interdisciplinaridade e intersetorialidade. Cienc. Saúde Colet., v. 12, n. 2, p. 363-72, 2007.

OSBORNE, D.; GAEBLERR, T. Reinventando o governo: como o espírito empreendedor está transformando o governo. Brasília: MH Comunicação. 1994

SANTOS, C. D. dos. Critérios de sustentabilidade socioambiental nas compras públicas: um estudo na Universidade Federal do Tocantins. 2016. 122f. Dissertação (Mestrado Profissional em Gestão de Políticas Públicas) Universidade Federal do Tocantins, Programa de Pós-Graduação em Gestão de Políticas Públicas, Palmas, 2016.

SGUISSARDI, V. Universidade brasileira no século XXI, desafios do presente. São Paulo: Cortez. 2009.

SILVA, R. C. da S.; BARKI, T. V. P. Compras públicas compartilhadas: a prática das licitações sustentáveis. Revista do Serviço Público, Brasília. v. 63, n. 2, p. 157-175. Abr./jun. 2012.

VERGARA, S. C. Projetos e relatórios de pesquisa em administração. 13. ed. São Paulo: Atlas, 2011. 